\title{
RESPONSABILIDAD PENAL JUVENIL: HACIA UNA "JUSTICIA INDIVIDUALIZADA"
}

\author{
Maite Aguirrezabal Grünstein* \\ Gladys Lagos Carrasco** \\ Tatiana Vargas Pinto***
}

\section{RESUMEN}

La principal diferencia del sistema penal juvenil está en las consecuencias jurídicas y sus criterios de selección. Conjuga dos ideas aparentemente opuestas: sanción y educación. Se asigna al juez la tarea de velar por su equilibrio. Así, la forma de decisión también cambia y su comprensión exige examinar principios, fines y características.

\section{RESPONSABILIDAD PENAL JUVENIL - SANCIÓN - EDUCACIÓN}

\section{Youth criminal justice: \\ Towards an "individualized justice"}

\begin{abstract}
The main feature of the Youth Criminal Justice System lies in the legal consequences and the criteria of selection. It combines two apparently opposite ideas: punishment and education. Judges are assigned with the task of watching over their balance. This way, the form of the decision changes and its understanding demands examining its principles, purposes and features.
\end{abstract}

YOUTH CRIMINAL JUSTICE - PENALTY - EDUCATION

* Abogada, Doctora en Derecho, Profesora de Derecho Procesal, Universidad de Los Andes, Av. San Carlos de Apoquindo 2200, Santiago de Chile. maguirrezabal@uandes.cl

** Abogada, Fiscal Judicial de la Corte de Apelaciones de Concepción, Directora Asociación Regional de Magistrados Concepción -Bío-Bío-Arauco, Chile.glagos@pjud.cl

*** Abogada, Doctora en Derecho, Profesora de Derecho Penal, Universidad de los Andes, Av. San Carlos de Apoquindo 2200, Santiago de Chile. tatianavp@uandes.cl

Artículo recibido el 22 de enero de 2009 y aceptado para su publicación por el Comité Editorial el 26 de octubre de 2009. 


\section{IMPLEMENTACióN DEL SISTEMA DE RESPONSABILIDAD PENAL ADOLESCENTE EN CHILE}

\section{Protección del adolescente y modelos de responsabilidad}

$\mathrm{E}$

1 aumento de delitos cometidos por jóvenes, e incluso niños, preocupa y reclama respuesta. ${ }^{1}$ Ésta no se puede adoptar sin tener en cuenta este especial actor o agente. Por eso conviene comenzar con una introducción sobre su condición frente al Derecho y las consecuencias de su conducta. Desde el inicio del siglo XX, calificado por algunos como "siglo del Niño", la comunidad internacional mostró interés por la protección de los derechos de los niños. Las Guerras Mundiales repercutieron gravemente en los menores de edad y su situación motivó la acción de organismos internacionales, como la Sociedad de las Naciones que en su V Asamblea de septiembre de 1924 adopta la "Declaración de Ginebra", primer instrumento internacional relativo a la protección de los derechos del niño. ${ }^{2}$

El niño se consideraba en esa época como un "objeto" de tutela, que determina el enfoque de la regulación existente. La primera ley sobre protección de menores, Ley 4.447 de octubre de 1928, tiene un carácter tutelar, crea la Dirección General de Protección de Menores, casas de menores y reformatorios. Destacan los modelos de protección del niño, pero prácticamente no existe legislación especial. Ante conductas ilícitas aparecen también modelos educativos y, más adelante, de responsabilidad. ${ }^{3}$ Si infringían leyes penales eran considerados incapaces y peligrosos. Requerían ser reeducados y si era necesario debían ser internados en los "reformatorios". 4

Posteriormente, en diciembre de 1948, las Naciones Unidas aprueba la "Declaración Universal de Derechos Humanos", que describe derechos reconocidos a todo ser humano sin distinción, por consiguiente incluye los niños. Ya en 1946 las Naciones Unidas crean el Fondo Internacional de Socorro, que actualmente conocemos como Fondo de las Naciones Unidas para la Infancia, UNICEF. En 1959, la Asamblea General de las Naciones Unidas aprueba la Declaración Universal de Derechos del Niño, que se considera

${ }^{1}$ Así lo registraban estadísticas sobre denuncias y aprehensiones entre los años 1995 y 2002, que analiza la Fundación Paz Ciudadana en su informe "Delincuencia Juvenil en Chile: Tendencias y Desafíos" de octubre de 2003. También el Mensaje de la Ley Nº 68-347, de 2 de agosto de 2002, subraya el evidente aumento de la preocupación social por la seguridad ciudadana en todos los ámbitos. Especial referencia a la creciente delincuencia juvenil se constata en la discusión parlamentaria.

${ }^{2}$ Este documento contenía un conjunto de principios humanitarios relativos al trato que debían recibir los niños, traducido en deberes básicos como: propender a su desarrollo físico y espiritual, proveer de alimentación, asistirlos en la enfermedad, procurar su educación, protección de la explotación económica, entre otros. Caracteriza esta Declaración el enfoque protector, que toma al niño como "objeto jurídico".

${ }^{3}$ Los primeros buscan soluciones fuera del ámbito judicial y los segundos admiten la asunción de consecuencias, aunque con un tratamiento diferenciado que limite medidas represivas, sobre todo si son privativas de libertad.

${ }^{4}$ La finalidad de este sistema era un control social de los niños que podían suponer un peligro y, sobre esa base, eran privados de sus derechos y garantías básicas. 
complemento de la Declaración Universal de Derechos Humanos. Se estructura con base en diez principios, donde destaca el derecho a gozar de una protección especial y su interés superior como guía fundamental. ${ }^{5}$

En el ámbito americano, cabe subrayar la Convención Americana de los Derechos Humanos, conocida como Pacto de San José de Costa Rica, promulgada en nuestro país el 5 de enero de 1991. ${ }^{6}$ Su art. 1.2 comienza con la declaración de que "persona es todo ser humano" y se ocupa de precisar una regla especial frente a las sanciones. El art. 4 $\mathrm{N}^{\circ} 5$ prescribe que "no se impondrá la pena de muerte a personas que, en el momento de la comisión del delito tuviere menos de 18 años de edad...". Por su parte, el art. 5 $\mathrm{N}^{\circ} 5$ dispone que "cuando los menores puedan ser procesados deben ser separados de los adultos y llevados ante Tribunales especializados, con la mayor celeridad posible, para su tratamiento". Especialmente respecto de los derechos del niño, el art. 19 señala que "todo niño tiene derecho a las medidas de protección que su condición de menor requieren por parte de su familia, de la sociedad y del Estado”.

Este panorama explica que en Chile se mantenga por largo tiempo el citado carácter tutelar. En 1967 se dicta la ley de Menores (Ley 16.618), que refunde legislaciones posteriores a la Ley 4.447, aplicable a los menores de 21 años. La mayoría de edad se rebaja a 18 años en junio de 1993 (Ley 19.221). En caso de infracciones a la ley penal, este menor de 18 años es inimputable en general, no responde. Como se sabe, se hacía una distinción entre tramos de edad: el menor de 16 años siempre era inimputable, por lo que nunca tenía responsabilidad y el mayor de esa edad y menor de 18 podía tener responsabilidad si se determinaba su discernimiento (antiguo art. 10, N $\mathrm{N}^{\text {os. }} 2$ y 3 del CP.). Éste era un trámite de cuyo resultado dependía la derivación del adolescente a la justicia del crimen $-\mathrm{y}$ su sometimiento al mismo procedimiento contemplado para adultos, con algunas reglas de atenuación- o a la de Menores, que le aplicaba una medida de protección que podía concretarse en una privación de libertad mediante la internación en establecimientos destinados para estos fines.

El instrumento internacional más importante que constituye la base de todos los cambios legislativos que se han registrado en nuestro país en la década del 90 y lo corrido de este siglo es la Convención sobre los Derechos del Niño (CDN), aprobada por la Asamblea General de la Naciones Unidas el 20 de noviembre de 1989 y promulgada como ley de la República de Chile por Decreto Supremo No 830 del Ministerio de Relaciones Exteriores, publicada en el Diario Oficial el 27 septiembre de 1990. Este tratado junto con las Reglas Mínimas de Naciones Unidas para la Administración de la Justicia de Menores, conocidas como "Reglas de Beijing" (Asamblea General Naciones Unidas, noviembre 1985); ${ }^{7}$ las Reglas de Naciones Unidas para Protección de Menores

\footnotetext{
${ }^{5}$ Es un documento muy breve, que sin embargo permitió abrir conciencia sobre los derechos humanos de la minoridad.

${ }^{6}$ DCTO N ${ }^{\circ} 873$ del Ministerio de RREE.

${ }^{7}$ Los principios generales son: procurar el bienestar del menor evitando en lo posible su paso por el sistema de justicia y si ello debe ocurrir, que sea lo menos perjudicial; proporcionalidad de la sanción, teniendo en cuenta la gravedad del delito y las circunstancias personales del joven; especialización de los intervinientes
} 
privados de Libertad (Asamblea General Naciones Unidas, abril 1991) ${ }^{8}$ y las Directrices de Naciones Unidas para la prevención de la Delincuencia Juvenil, "Directrices de RIAD" (Asamblea General Naciones Unidas, abril 1991), ${ }^{9}$ consagran la llamada "doctrina de la Protección Integral del Niño". ${ }^{10}$

A partir de la CDN y hasta la dictación de la Ley de Tribunales de Familia (agosto de 2004) se hizo una serie de modificaciones a la Ley 16.618, como la prohibición de ingreso de menores a Establecimientos Penitenciarios de adultos (Ley 19.343 de 31 octubre, 1994), producto del compromiso que adquiere Chile de dar a conocer esos principios y disposiciones y adecuar su legislación a ellos. ${ }^{11}$ El principio central de las reformas y nuevos cuerpos legales es el interés superior del niño, que también repercute al examinar conductas infractoras. En este sentido, las normas reflejan otro modelo de responsabilidad, uno que la admite precisamente a partir del reconocimiento de los derechos del niño. Como sujeto de derechos, el joven también es responsable de sus actos. Asume las consecuencias de su comportamiento, claro que de acuerdo a su nivel de desarrollo, según las reglas y principios impuestos.

Si bien destacan otros modelos, como el educativo y el de "justicia restaurativa", ${ }^{12}$ es el modelo de responsabilidad el que cambia la perspectiva para enjuiciar la conducta del menor de edad. Éste puede asumir las consecuencias de su conducta, pero no de la misma forma que un adulto plenamente desarrollado. El sistema de responsabilidad penal que hoy rige en nuestro país pretende conciliar la asunción de responsabilidad

en el proceso; respeto de garantías procesales básicas, presunción de inocencia, derecho a defensa, etc., la privación de libertad como último recurso y un amplio catálogo para tratamiento y educación del menor.

${ }^{8}$ La idea central de estas reglas es que el sistema de justicia de menores debe respetar su seguridad y derechos; fomentar su bienestar físico y mental, así como la imposición de la privación de libertad por el período mínimo necesario y en casos excepcionales, esto es, como último recurso. Asimismo, reglamenta condiciones básicas que deben tener los Centros de Internación: educación, salud, higiene, alimentación, actividades recreativas y religiosas, visitas, régimen disciplinario, programas de reintegración y formación especializada de su personal.

${ }^{9}$ Las reglas y directrices no son vinculante, aunque la CDN cita las Reglas de Beijing en su preámbulo.

${ }^{10}$ El principio básico es que la prevención de la delincuencia juvenil es parte esencial de la prevención del delito en la sociedad. Para ello es necesario que toda la sociedad procure el desarrollo armonioso de los adolescentes. Los programas deben centrarse en el bienestar de los jóvenes desde su primera infancia. Ya Cillero Bruñol, Miguel et al., Niños y Adolescentes: Sus derechos en nuestro Derecho, SENAME, Santiago, 1995, pp. 80-84, señalaban que esta doctrina de la protección integral debía entenderse en términos amplios y no restringidos, referida a la “'dignidad humana' en general”.

${ }^{11}$ Las modificaciones del Código Civil en materia de filiación, la ley de Adopción, la Ley de VIF, la que creó los Tribunales de Familia y la ley de RPA han sido el resultado de la ratificación de la CDN.

12 Un modelo únicamente educativo escapa de respuestas sancionatorias y pretende sólo brindar un tratamiento. Por su parte, el modelo de justicia restaurativa es un medio alterno para resolver conflictos dirigido a reparar el daño cometido. Tiene en consideración a la víctima, pero también se supone una medida socioeducativa. Esta idea recoge de cierta forma en el actual sistema nacional: dentro de la gama de medidas contempladas está la posibilidad de imponer la reparación del daño causado (art. 6 letra f), Ley 20.084). 
con la idea de educar y reinsertar socialmente a este particular actor. Así lo establece expresamente el art. 20 de la Ley 20.084. ${ }^{13}$

\section{Recepción del modelo de responsabilidad penal actual}

La CDN se ocupa de todas las dimensiones de la vida y el desarrollo de los niños y en diversos ámbitos: promueve acciones políticas, socioeconómicas y educativas cuyo fin es su protección. Se reconoce que el niño no es menos relevante que el adulto, es simplemente un ser humano en la primera etapa de su desarrollo. Su preámbulo precisa que se tiene especialmente en cuenta que "el niño, por su falta de madurez física y mental, necesita protección y cuidados especiales, incluso la debida protección legal, tanto antes como después del nacimiento". Infancia y adolescencia son etapas del desarrollo humano y tienen igual valor que cualquier período de su existencia. ${ }^{14}$ Estas consideraciones se proyectan en principios que han influido en las regulaciones de diversos países a partir de la última década del siglo XX: el niño sujeto de derecho; ${ }^{15}$ el interés superior del niño; ${ }^{16}$ la protección integral de los derechos del niño, ${ }^{17}$ así como la autonomía progresiva del niño en el ejercicio de sus derechos.

Este último principio se relaciona con la consideración del niño y el adolescente como sujeto de derecho y se basa en su nivel de desarrollo. Conforme el niño va creciendo y desarrollando, también sus facultades evolucionan progresivamente. El Estado y las familias deben conferirle la orientación y protección apropiada a esa evolución. La

${ }^{13}$ Importan aspectos educativos y sancionatorios gracias a la consideración de este particular agente. Roca Agapito, L., El sistema de sanciones en el Derecho penal español, J.M. Bosch, Barcelona, 2007, p. 420, subraya esta combinación y agrega que una de las características más relevantes de este modelo es la amplia gama de medidas que se establecen. Fórmula que, como veremos, acoge nuestro sistema. También Cillero Bruñol, et al, Niños y Adolescentes..., pp. 81 (nota 4), 91-94, entendían, ya en 1995, que el modelo de responsabilidad no se oponía al tutelar y que la CDN recogía - recoge- esta combinación como propuesta.

${ }^{14} \mathrm{La}$ CDN entiende por "niño" todo ser humano menor de 18 años de edad. No distingue entre niños $\mathrm{y}$ adolescentes.

${ }^{15}$ Se reconocen las necesidades básicas de los niños como derechos, y también establece las responsabilidades de la familia, la sociedad y el Estado para que esos derechos sean reconocidos y respetados. Es el concepto base y trasversal en todo el documento. Constituye una nueva concepción del niño en oposición a la doctrina del "niño en situación irregular", con un niño como objeto de protección.

${ }^{16} \mathrm{La}$ CDN dispone que todas las medidas concernientes a la niñez que tomen las instituciones públicas o privadas de cualquier índole han de atender al interés superior del niño, pero no se define. Cillero Bruñol, et al., Niños y Adolescentes..., pp. 84-86, señalan que es un criterio orientador que pretende realizar justicia y no un objetivo social deseable. Así, consideran que no es un principio vago, pues tiene un contenido: satisfacer los “derechos humanos” del niño, que sirve de guía y límite. En similares términos, Cerda San Martín, Mónica; Cerda San Martín, Rodrigo, Sistema de responsabilidad penal para adolescentes, $2^{\mathrm{a}}$ ed., Librotecnia, Santiago, 2007, pp. 37-44. Bustos Ramírez, Juan, Derecho penal del niño-adolescente (estudio de la Ley de responsabilidad penal adolescente). EJS, Santiago, 2007, pp. 19-22, destaca esta opinión de varios autores -entre ellos Cilleros-en sentido de buscar dar al principio un "campo operativo concreto". Agrega que, para que ello se logre, este interés superior del niño ha de referirse a los conflictos que los niños tengan con otros.

${ }^{17}$ Implica protección igualitaria a todos los niños sin distinción de sexo, raza, condición social, etc. Supuso, entre otras modificaciones, la eliminación en nuestras leyes de la diferencia entre hijos legítimos, naturales e ilegítimos. 
adolescencia no es una etapa que se exime de esta guía, sino que la requiere. El joven está expuesto a riesgos, pasa por una fase vulnerable a influencias de diversa clase, personales y circunstanciales. La situación en que vive también juega un rol importante a la hora de comportarse de una u otra forma. Hoy, es cada vez más frecuente constatar la comisión de delitos por jóvenes cada vez menores, niños de baja condición económica, social y cultural. ${ }^{18}$ ¿Hasta qué punto el entorno favorece la evolución negativa del niño? Estas condiciones no son determinantes, como sí podrían serlo alteraciones mentales o factores genéticos, pero el menor desarrollo del niño, niña y adolescente es un hecho que ha de apreciarse al momento de apreciar su conducta.

Justamente, fruto del principio de la autonomía progresiva adquiere relevancia la determinación de la edad y características de este sujeto (niño-adolescente) a la hora de exigir su responsabilidad frente a la comisión de un ilícito penal, la infracción de la ley penal. El distinto grado de evolución de sus facultades intelectuales y volitivas exige valorarlas según su desarrollo para determinar si procede asignar una consecuencia a sus actos y cuál ha de ser ésta. De allí que -en un principio- se determina la inimputabilidad del niño infractor, es decir, una edad mínima en la que no puede tener responsabilidad penal. ${ }^{19}$ La gravedad de la sanción demanda particular cautela al enjuiciar la gravedad de la conducta del menor, según sus posibilidades de comprensión y decisión. Luego, a partir de la edad en que se establece su responsabilidad, ésta ha de ser acorde con sus circunstancias particulares. Su comportamiento ha de medirse conforme sus condiciones, no de la misma forma que un adulto. ${ }^{20}$

De acuerdo con estos lineamientos, nuestra ley crea un régimen especial de responsabilidad para adolescentes entre los 14 y 18 años de edad, que entra en vigencia en el año 2007 (Ley 20.084). Comienza por establecer la responsabilidad del joven, pero con la precisión de que ella ha de enfocarse hacia su resocialización (arts. 1 y 3). Ideas que plasman justamente en las consecuencias jurídicas que se imponen -aunque se observe que faltan reglas para la apreciación especial de las conductas (delitos)-. De este modo se dispone un amplio listado de sanciones (art. 6) y se limita la privación de libertad como respuesta (arts. 26 y 47 ).

${ }^{18}$ Cifras que presenta UNICEF reflejan este aumento de la delincuencia “infanto-juvenil”. La mayoría proviene de familias pobres y marginadas, aunque también se registra un importante número de niños y jóvenes de mejor situación, clase media y alta, con un denominador común: la falta de atención y cuidados de sus padres. Ver UNICEF, Índice de Infancia, una mirada comunal y regional, Santiago, 2002; asimismo, Donovan, Patrick; Oñate, Ximena; Bravo, Gonzalo; Rivera, M. Teresa, "Niñez y Juventud en Situación de Riesgo: La Gestión Social del Riesgo. Una revisión bibliográfica”, Última Década, No 28, vol. 16, Santiago, 2008, http:// www.scielo.cl/scielo.php? script $=$ sci_arttext\&pid $=$ S0718-22362008000100004\&lng $=$ en\&nrm $=$ iso

${ }^{19}$ Así lo establece el art. 40. 3 a) de la CDN, una edad dentro de la que se presume que el niño no tiene capacidad para infringir la ley penal.

${ }^{20} \mathrm{La}$ CDN también se pronuncia en este sentido. Señala que se pueden tomar medidas si son "apropiadas y deseables" [art. 40.3 b)] y describe una serie de medidas que se pueden adoptar y siempre "para asegurar que los niños sean tratados de manera apropiada para su bienestar y que guarde proporción tanto con sus circunstancias como con la infracción” (art. 40. 4). 
Además de los instrumentos internacionales, las legislaciones de Brasil (Estatuto del Niño y del Adolescente data de 1990) y Costa Rica (Ley de Justicia Penal Juvenil) inspiran el actual sistema nacional. Cabe anotar, sin embargo, que ambas regulaciones consideran como "niño" al menor de hasta 12 años de edad, por lo que desde esa edad surge la responsabilidad del adolescente. ${ }^{21}$ En esta materia seguimos la legislación española, Ley Orgánica $N^{\circ} 5$ de 12 de enero de 2000, que fija la responsabilidad penal de los jóvenes a partir de los 14 años de edad. ${ }^{22}$

\section{ROL DEL JUEZ: PRINCIPIOS Y CRITERIOS DE DECISIÓN}

\section{Principios que rigen el rol del juez}

El régimen de responsabilidad penal que instaura nuestro legislador para los adolescentes infractores acoge en general la doctrina de la protección integral del niño, niña y adolescente ${ }^{23}$ y tiene como base el interés superior del niño, ${ }^{24}$ aun cuando se trata de juzgar una conducta ilícita. En este sentido, destaca tanto la forma en que se establece la responsabilidad como el modo en que se mide o concreta en determinadas consecuencias. Aquí, la labor del juzgador es elemental y su estudio se enmarca dentro de un determinado modelo de justicia, que ha de examinarse para detenerse en el ejercicio de sus facultades de acuerdo con su rol.

Los rasgos más característicos de este nuevo sistema son el mayor acercamiento a la justicia penal de adultos en lo que se refiere a derechos y garantías individuales, por un refuerzo de la posición legal de los jóvenes y una mayor responsabilidad de estos actores por sus actos delictivos. Se reconoce responsabilidad para un mayor rango de sujetos, pero se limita al mínimo indispensable la intervención de la justicia penal, con una amplia gama de sanciones como respuesta jurídica al delito, basadas en principios educativos y en la reducción al mínimo de sanciones privativas de libertad (arts. 26, 47), ${ }^{25}$ de suerte que el juez debe preferir medidas de otra naturaleza, como la libertad

${ }^{21}$ Otras legislaciones, como las de México y Ecuador, contemplan también la responsabilidad penal a partir de los 12 años de edad. En el mismo sentido, el Código de los Niños y Adolescentes de Perú considera adolescente al joven de 12 años (siempre hasta los 18).

${ }^{22}$ Asimismo, hay sistemas que fijan la responsabilidad penal desde los 16 años, como la Ley 22.278 de la Argentina.

${ }^{23}$ La publicación de la Ley 20.084 es un reflejo de la adecuación de la legislación chilena a los tratados celebrados y ratificados por nuestro país, y que se enmarca dentro del mismo criterio de adecuación a la normativa internacional que motivó la publicación de la Ley 19.968, sobre tribunales de familia.

${ }^{24}$ Como un conjunto de derechos de los niños, niñas y adolescentes ha de servir no sólo de guía, sino especialmente de límite para la autoridad.

25 También muestra esta limitación de las penas privativas de libertad el art. 19 al contemplar la posibilidad de sanciones mixtas: "En los casos en que fuere procedente la internación en régimen cerrado o semicerrado, ambas con programa de reinserción social, el tribunal podrá imponer complementariamente una sanción de libertad asistida en cualquiera de sus formas, por un máximo que no supere el tiempo de la condena principal". 
asistida o la prestación de servicios a la comunidad (art. 6). Únicamente ha de imponer la internación en régimen cerrado, con programa de reinserción social, si la extensión de la pena supera los cinco años (art. $\left.23 \mathrm{~N}^{\circ} 1\right) .{ }^{26}$ Por otra parte, se da mayor atención a la víctima, bajo la concepción de la necesidad de reparación del daño causado (art. 6 letra f). Se destaca la idea de desjudicializar la respuesta por medio de controles formales, como el principio de oportunidad, la conciliación entre el autor y la víctima, la suspensión del proceso a prueba y la condena de ejecución condicional sin limitaciones. ${ }^{27}$

Consecuencia de un modelo de responsabilidad que considera al adolescente sujeto a una regulación especial en todos los ámbitos de su desarrollo -sea éste social, psíquico o jurídico-, el sistema penal juvenil ha adoptado una concepción punitivo-garantista: se le atribuye al menor de edad una mayor responsabilidad, pero, a su vez, se le reconoce una serie de garantías sustantivas y procesales que no eran siquiera pensadas en la concepción tutelar. $^{28}$ Dentro de este modelo se establece un marco de legalidad con respecto a la forma en que el juez debe aplicar las sanciones, pero también se concede cierto margen de libertad para decidir, tanto al señalar las consecuencias como los criterios para su determinación. La gran novedad del sistema está en el aspecto sancionatorio. Para comprender el ejercicio de la potestad sancionadora hay que analizar los principios básicos que rigen la decisión del juez al momento de determinar la respuesta adecuada en un procedimiento de esta naturaleza. ${ }^{29}$ Según el carácter impulsado por los instrumentos internacionales, cabe citar: el principio de la prevención por sobre el de la sanción, el principio de desformalización de la justicia penal juvenil, el de preferencia de las sanciones no privativas de libertad y la vigencia del principio educativo en la determinación y ejecución de las sanciones.

\footnotetext{
${ }^{26}$ Aun en esos casos la sanción se puede modificar durante el control de su ejecución, según se expone más adelante.

${ }^{27}$ Sobre la especialización de la justicia penal adolescente, el legislador optó por una especialización de los intervinientes en este nuevo proceso en la materia y no por la creación de tribunales especializados, aunque esta especialización se limita a exigir cursos de capacitación, lo que constituye un piso mínimo en la materia, y permitiendo la intervención de fiscales, jueces y defensores no especializados en casos que sólo podrían justificarse por motivos de distribución del trabajo.

${ }^{28}$ La extensión de garantías procesales es propia de este modelo. Ver Giménez-Salinas Colomer, E., "La justicia de menores en el siglo XX. Una incógnita", en Un Derecho penal del menor, Bustos Ramírez, J. (Dir.), ConoSur, Santiago, 1992, p. 21. La regulación no es sólo procesal, sino también de fondo. Cfr., Llobet Rodríguez, J., "La justicia penal juvenil en el Derecho internacional de los derechos humanos", en Anuario de Derecho Constitucional Latinoamericano, México, 2002, p. 5. Sin perjuicio de ello, la Ley 20.084 contempla una reforma básicamente procesal, pues son escasas las disposiciones de Derecho penal sustantivo. La mayor innovación tiene que ver con las penas y sus criterios de determinación, ya que los sujetos siguen atados a las reglas generales del Código Penal.

${ }^{29}$ Bustos Ramírez, J., Obras completas. Control Social y otros estudios, ARA, Lima, 2004, t. II, pp. 656-658, recoge como principios: el galantismo, la descriminalización, la desjudicialización, la prioridad de formas ambulatorias de sanción y la distinción terminante entre responsabilidad del niño y protección del niño.
} 


\subsection{El principio de prevención por sobre el de la sanción}

Uno de los principios fundamentales del "Derecho penal juvenil", propio de la doctrina de la protección integral del niño, niña y adolescente, es aquel que da prioridad a la prevención antes que a la sanción. Se parte del axioma de que la delincuencia juvenil se combate principalmente a través de una buena política social más que por una adecuada política penal. Puede decirse que esta idea de prevención incluso se refleja en el mismo sistema penal, al preferir sanciones no privativas de libertad y considerar criterios de prevención futura (resocialización).

\subsection{Principio de desformalización o desjudicialización de la justicia penal juvenil}

La tendencia en el Derecho penal juvenil es a la desformalización, que trata de evitar que se imponga una sanción propiamente dicha, a través de soluciones de justicia restaurativa, ${ }^{30}$ o bien el archivo del asunto a través de la aplicación de criterios de oportunidad reglados. Lo que se pretende es evitar el pronunciamiento de una sentencia condenatoria con su carácter estigmatizador y la imposición de una sanción, especialmente la privativa de libertad. La desformalización de los procedimientos surge como consecuencia de las características propias de este régimen, del énfasis en criterios de reinserción social. Esto mismo explica la necesidad de flexibilizar la aplicación de las penas. ${ }^{31}$ En los últimos tiempos esta tendencia a la desformalización se aprecia también en el sistema penal de adultos, que ha llegado a aprobar también recomendaciones en el ámbito de la ONU en ese sentido. ${ }^{32}$

En la CDN, el artículo 40 inciso 3) b) dispone que los Estados promoverán: "Siempre que sea apropiado y deseable, la adopción de medidas para tratar a esos niños sin recurrir a procedimientos judiciales, en el entendimiento de que se respetarán los

\footnotetext{
${ }^{30}$ Se ha de recordar que cuando se habla de justicia restaurativa se hace mención a un movimiento que enfatiza la ofensa a la víctima por el delito, de modo que se considera que ella misma debe intervenir en la resolución del conflicto. Se le da importancia fundamentalmente a la conciliación víctima-autor, más que a la imposición de una sanción o pena. En este sentido, ver Roig Torres, M., La reparación del daño causado por el delito, Tirant Lo Blanch, Valencia, 2000, pp. 365-367; Pérez Sanzberro, G., Reparación y conciliación en el sistema penal, Comares, Granada, 1999, pp. 15-18.

${ }^{31}$ El Mensaje de la ley precisa que "Siguiendo la más moderna doctrina, el Proyecto recepciona todas las garantías penales y procesales propias de los adultos, agregando garantías específicas para los adolescentes. En particular se establece un criterio flexible, a favor del adolescente, en la adjudicación de sanciones; la posibilidad de dejar sin efecto o sustituir anticipadamente las sanciones por otras menos severas; facultades de control jurisdiccional de la ejecución que garanticen los derechos del condenado y el cumplimiento efectivo de las sanciones". La Exposición de Motivos de la LO española 5/2000, establece como principio general la "naturaleza formalmente penal pero materialmente sancionadora-educativa del procedimiento y de las medidas aplicables a los infractores menores de edad".

32 A lo anterior hacen referencia, por ejemplo, la declaración de la ONU sobre los principios fundamentales de justicia para las víctimas de delitos y del abuso del poder de 1985 y las normas para la aplicación de dicha declaración de 1989. Véase también: la recomendación No R (85) 11 del Comité de Ministros de los Estados miembros del Consejo de Europa de 1985.
} 
derechos humanos y las garantías legales”. El principio de ultima ratio y la desformalización están expresados en la regla 11 de las Reglas de Beijing. ${ }^{33}$ En el ámbito europeo es importante mencionar la Recomendación número R (87) 20 del Comité de Ministros del Consejo de Europa, en la que se aconsejó "2. Alentar el desarrollo de procedimientos de desjudicialización y de mediación a nivel del órgano de prosecución (clasificación sin persecución) o a nivel policial, en los países donde la Policía tenga funciones de persecución, a fin de evitar a los menores la asunción por el sistema de justicia penal y las consecuencias derivadas de ello; asociar a los servicios o comisiones de protección a la infancia de estos procedimientos" y "3. Adoptar las medidas necesarias para que en el curso de estos procedimientos: - se aseguren la aceptación por el menor de las eventuales medidas que condicionan la desjudicialización y, si es preciso, la colaboración de su familia; - se conceda una atención adecuada tanto a los derechos e intereses de la víctima como a los del autor". A su vez, la Corte Interamericana de Derechos Humanos se pronunció con respecto a la desformalización del procedimiento penal seguido contra adolescentes, en la Opinión Consultiva OC-17/2002 del 28 de agosto del 2002, en pro de medidas alternativas a la sanción. ${ }^{34}$

\subsection{Flexibilidad en la adopción y ejecución de las consecuencias jurídicas}

Como vimos, la desformalización judicial repercute en las consecuencias jurídicas que cabe imponer, en la naturaleza de las sanciones y su forma de determinación. La adecuación de la sanción a la conducta y condición del joven infractor exige la flexibilidad suficiente para valorar la gravedad de la infracción y seleccionar la respuesta en el caso concreto. Nuestro legislador no es ajeno a este proceder. La Ley 20.084 y su Mensaje son claros. Éste presenta como uno de sus objetivos el fijar un sistema de responsabilidad adecuado a los adolescentes entre 14 y 18 años, pero considerándolos como sujetos de

${ }^{33}$ Esta regla dispone que "11.1) Se examinará la posibilidad, cuando proceda, de ocuparse de los menores delincuentes sin recurrir a las autoridades competentes, mencionadas en la regla 14.1 infra, para que los juzguen oficialmente; 11.2) La policía, el Ministerio Público y otros organismos que se ocupen de los casos de delincuencia de menores estarán facultados para fallar dichos casos discrecionalmente con arreglo a los criterios establecidos al efecto, y sin necesidad de visita oficial, en los respectivos sistemas jurídicos y también en armonía con los principios contenidos en las presentes reglas; 11.3.) Toda remisión que signifique poner al menor a disposición de las instituciones pertinentes de la comunidad o de otro tipo, estará supeditada al consentimiento del menor o al de sus padres o tutor; sin embargo, la decisión relativa a la remisión del caso se someterá al examen de una autoridad competente, cuando así lo solicite y 11.4.) Para facilitar la tramitación discrecional de los casos de menores, se procurará facilitar a la comunidad programas de supervisión y orientación temporales, restitución y compensación de víctimas”.

${ }^{34}$ Dispuso en dicha Opinión Consultiva que las normas internacionales procuran excluir o reducir la 'judicialización' de los problemas sociales que afectan a los niños, que pueden y deben ser resueltos, en muchos casos, con medidas de diverso carácter, al amparo del artículo 19 de la Convención Americana, pero sin alterar o disminuir los derechos de las personas. En este sentido, "son plenamente admisibles los medios alternativos de solución de las controversias, que permitan la adopción de decisiones equitativas, siempre sin menoscabo de los derechos de las personas. Por ello, es preciso que se regule con especial cuidado la aplicación de estos medios alternativos en los casos en que se hallan en juego los intereses de los menores de edad". 
derecho que deben ser tratados con especial diligencia. Habla de exigir una "responsabilidad especial adecuada a su carácter de sujeto en desarrollo", que busca "considerar al adolescente como un sujeto de derecho que debe ser protegido en su desarrollo e inserción social y lograr objetivos de prevención de delito". Las consecuencias que se imponen son sanciones que persiguen la educación del condenado. Se evidencia tanto en los programas que se contemplan y la variedad de consecuencias - donde la privación de libertad (internación) es excepción- como también en las reglas y criterios de determinación de penas que permiten considerar la situación del adolescente. ${ }^{35}$ De ahí entonces que las sanciones aplicadas a estos sujetos no deben tener un carácter únicamente punitivo, sino que deben considerar su desarrollo personal, su nivel de educación, el medio en el que se desenvuelve, sus posibilidades de reinserción en la sociedad, etc.

Esto explica que la ley haya otorgado gran preponderancia a soluciones alternativas de terminación procesal, tales como la suspensión de la aplicación de la pena ${ }^{36}$ o la suspensión condicional del procedimiento. El legislador incluso ha ido más allá, alterando el régimen normal de la cosa juzgada y estableciendo la posibilidad de que una sentencia dictada en un procedimiento de esta naturaleza pueda ser luego modificada o dejada sin efecto a través de la figura de la sustitución de la condena, contemplada en el art. 53 inciso $1^{\circ} .37$

Por lo tanto, el rol del juez en el procedimiento es distinto al que normalmente desempeña. Primero, porque los factores a considerar en la determinación de la pena (medida) son mucho más amplios que en otros procedimientos y porque implican la referencia a distintas disciplinas, no todas del orden jurídico. Ello, sin perjuicio de que se le impongan ciertos límites en casos de mayor gravedad, cuando la extensión de la pena supera los cinco años. En tales situaciones, aunque el juez debe imponer una pena privativa de libertad, siempre ha de aplicar un programa de reinserción social y verificar la necesidad de su conservación. Así, posee también amplias facultades con relación al

${ }^{35}$ Su condición se toma en cuenta también por el legislador, al establecer el sistema de responsabilidad, pero especialmente a la hora determinar la sanción. El mismo Mensaje asume la tipicidad pero precisa que "se establece un criterio de intervención penal especial reducida o moderada, tanto en relación a los delitos, como a las sanción”. En este sentido, Hernández Basualto, H., "El nuevo Derecho penal de adolescentes y la necesaria revisión de su teoría del delito”, en Revista de Derecho (2007), vol. XX, No 2, pp. 203-205, extiende las reglas especiales de los tipos sexuales a otros, por su fundamento, el fin de protección de la norma. Afirmar que los tipos no se explican igual respecto de la conducta de los jóvenes implica tomar criterios de necesidad a la hora de apreciar el comportamiento frente al tipo y a lo injusto.

${ }^{36}$ Figura prevista en el artículo 41 de la Ley, que dispone que "cuando hubiere mérito para aplicar sanciones privativas o restrictivas de libertad iguales o inferiores a 540 días, pero concurrieren antecedentes favorables que hicieren desaconsejable su imposición, el juez podrá dictar la sentencia y disponer en ella la suspensión de la pena y sus efectos por un plazo de seis meses".

${ }^{37} \mathrm{El}$ artículo 53 inciso $1^{\circ}$ de la Ley dispone que "el tribunal encargado del control de la ejecución de las sanciones previstas en esta ley, de oficio o a petición del adolescente o su defensor, podrá sustituirla por una menos gravosa, en tanto ella aparezca más favorable a la integración social del infractor y se hubiere iniciado su cumplimiento". Debemos entender que al hablar el artículo de "iniciado su cumplimiento", nos encontramos ante una situación en la que ya existe una sentencia condenatoria que se encuentra actualmente ejecutándose, y de ahí entonces la flexibilización del régimen de la cosa juzgada en esta clase de sentencias. 
control de la ejecución de las medidas, que en el caso de Chile corresponde al juez de garantía. ${ }^{38}$ En este sentido, se admite que en nuestro sistema la pena tiene este carácter flexible, desde el minuto que es el propio legislador quien la considera parte de una intervención socioeducativa amplia, que busca la reaserción plena del adolescente. ${ }^{39}$

\subsection{Principio de preferencia de las sanciones no privativas de libertad}

Constituye un principio elemental del Derecho penal de adolescentes el que en los casos en que no es posible aplicar medidas alternativas a la sanción y se ha dictado en contra del joven una sentencia condenatoria que supone la imposición de una sanción, las penas privativas de libertad constituyen un último recurso. Este carácter de ultima ratio de la sanción privativa de libertad es un principio consagrado en reglas internacionales y se traduce en el establecimiento de sanciones diferentes a las privativas de libertad, que se aplican de modo preferente a ellas. ${ }^{40}$

\subsection{Preponderancia del principio educativo en la determinación y ejecución de las sanciones}

El principio educativo parece ser el centro de todos los demás, pues desempeña un papel de protección de los derechos fundamentales del adolescente sometido a la justicia penal juvenil y suavizando la reacción penal estatal. Tiene además gran importancia en la ejecución de las sanciones, en especial con aquellas que dicen relación con la privación de libertad. Sobre este punto, las Reglas de Beijing disponen que "36.1. La capacitación y el tratamiento de menores confinados en establecimientos penitenciarios tienen por objeto garantizar su cuidado y protección, así como su educación y formación profesional para permitirles que desempeñen un papel constructivo y productivo en la sociedad" y “36.2. Los menores confinados en establecimientos penitenciarios recibirán los cuidados, la protección y toda la asistencia necesaria -social, educacional, profesional, sicológica, médica y física- que puedan requerir debido a su edad, sexo y personalidad y en interés de su desarrollo sano".

${ }^{38}$ El legislador crea la figura del “juez de control de la ejecución”, función que desempeña un juez de garantía del lugar en que la sanción deba cumplirse y vela por la verificación de la legalidad de la ejecución y tomar las medidas del caso si hay violaciones de la misma, resolver los quebrantamientos y fallar las solicitudes de revisión (sustitución o remisión) de las sanciones originalmente impuestas.

${ }^{39}$ Ver Cerda San Martín, M.; Cerda San Martín, R., Sistema..., pp. 44-47, 145 y 147. Sí, advierten el peligro de que la consideración de las características personales opere en contra del joven imputado (p. 130).

${ }^{40}$ Sobre este punto, señalan las Reglas de Beijing en su numeral 18.1: "Para mayor flexibilidad y para evitar en la medida de lo posible confinamiento en establecimientos penitenciarios, la autoridad competente podrá adoptar una amplia diversidad de decisiones. Entre tales decisiones, algunas de las cuales pueden aplicar simultáneamente, figuran las siguientes: a) Órdenes en materia de atención, orientación y supervisión; b) Libertad vigilada; c) Órdenes de prestación de servicios a la comunidad; d) Sanciones socioeconómicas, indemnizaciones y devoluciones; e) Órdenes de participar en sesiones de asesoramiento colectivo y en actividades análogas; g) Órdenes relativas a hogares de guarda, comunidades de vida u otros establecimientos educativos; h) Otras órdenes pertinentes". 
La normativa entrega al juez facultades de control y fiscalización en la fase de ejecución de la pena y "tal finalidad fundamenta claramente los mecanismos de revisión de sanciones que se crearon. En todo caso, es indudable que también están presentes finalidades de prevención general y de inocuización, pues sólo ello podría explicar la ampliación de las penas privativas de libertad hasta 10 años”. 41

\section{Reglas de determinación de las medidas}

A diferencia de lo que sucede en el sistema penal de adultos, en el que cada delito tiene señalada una pena específica, en el régimen penal de adolescentes no sucede así. En principio, el Juez podrá imponer cualquiera de las medidas previstas en los artículos 6 y siguientes de la Ley 20.184, aunque con ciertas reglas específicas para determinados delitos, como en el caso de ilícitos cuyas penas excedan los cinco años de duración (art. 23, $\mathrm{N}^{\mathrm{o}} 1$ ), que exigen la imposición de una sanción privativa, y sin perjuicio de que el juez deba motivar la sentencia expresando en detalle las razones por las que se aplica una medida en cuestión.

La ley contiene tres tipos de sanciones, a saber: sanciones educativas; sanciones de orientación y supervisión y sanciones privativas de libertad. ${ }^{42}$ Las sanciones educativas contemplan la amonestación, la libertad asistida, la prestación de servicios a la comunidad, la reparación de los daños causados a la víctima y la prohibición de conducir vehículos motorizados. Ante el requerimiento de la pluralidad de sanciones, y con el fin de que prevalezca el principio de la intervención mínima, el juez puede aplicar las sanciones educativas en aquellos casos en los que el bien jurídico afectado no sea de carácter fundamental o, aun en ese caso, cuando la afectación ha sido leve y se considere que, por las condiciones personales del sujeto, este tipo de respuestas son las más adecuadas. El período máximo de duración de estas sanciones es diferente en cada una de ellas. En el caso de la libertad asistida, ese período es de tres años; en el caso de la prestación de servicios a la comunidad es de 120 horas, y en el caso de la reparación de daños, cuando se confirme la suficiencia de la reparación del daño por parte del juez.

Las sanciones de orientación y supervisión se componen de diversas obligaciones que le son impuestas al adolescente, y que en nuestra legislación se reflejan en la imposición de sanciones accesorias, tales como la obligación de someterse a tratamientos de rehabilitación para superar la adicción a las drogas o al alcohol. ${ }^{43}$ El fundamento de este tipo de sanciones, al igual que con las educativas, se encuentra en el objetivo de evitar la imposición de una sanción más grave.

${ }^{41}$ Berríos Díaz, G., "El nuevo sistema de justicia penal para adolescentes", en Revista de Estudios Justicia Facultad de Derecho, Universidad de Chile, N 6, 2005, p. 167.

${ }^{42}$ Las sanciones se regulan a partir del art. 6 y el artículo 24 de la citada Ley establece los criterios en virtud de los cuales el juez debe determinar la pena, destacando, entre otros, la gravedad del ilícito de que se trate, la edad del adolescente infractor y la idoneidad de la sanción para fortalecer el respeto del adolescente por los derechos y libertades de las personas y sus necesidades de desarrollo e integración social.

${ }^{4}$ Sanción prevista como accesoria en el artículo $7^{\circ}$ de la Ley. 
Por último, la ley dispone acerca de las sanciones privativas de libertad. Se regulan dos tipos de "internación”, a saber: el sistema de internación en régimen semicerrado con programa de reinserción social y el sistema de internación en régimen cerrado con programa de reinserción social. Este último tipo de sanciones tienen un carácter excepcional o de ultima ratio, y su imposición debe ser la respuesta a conductas que lesionan, de manera grave, bienes jurídicos fundamentales de la sociedad, estableciéndose un límite máximo de cinco o diez años para la duración de estas penas. ${ }^{44}$ Las sanciones privativas de libertad se cumplen en centros especializados dependientes del Servicio Nacional de Menores (Sename), que es el encargado de administrar estos centros y de desarrollar los programas necesarios para la ejecución y control de las medidas que se impongan.

\section{LA DECISIÓN DEL JUZGADOR FRENTE A UN MODELO DE JUSTICIA INDIVIDUALIZADA}

\section{Ejercicio de la potestad sancionadora}

La muerte de Pedro causada por Juan, de 15 años de edad, no sólo debe ser investigada, sino también juzgada por un tribunal penal que ha de establecer tanto la conducta ilícita como su participación en los hechos. El reconocimiento de la responsabilidad penal de los menores de 18 años y mayores de 14 exige que el juez examine el comportamiento de estos jóvenes, si cumple o no con los elementos del delito y, sobre todo, la consecuencia que cabe aplicar si procede. Este conocimiento y juzgamiento se someten a reglas y principios del régimen de responsabilidad que los rige. El ejercicio de la potestad sancionadora del juez en estos casos tiene rasgos particulares que han de examinarse.

Este ejercicio no alcanza conductas ejecutadas antes de la vigencia del actual sistema. Así, la sentencia de la Corte de Apelaciones de San Miguel de septiembre de $2008^{45}$ dispone su improcedencia si al momento de infringir la ley penal correspondía realizar el trámite de discernimiento y no se hizo. Parece lógica la aplicación no retroactiva de una ley que crea un sistema de responsabilidad a quien no la tenía antes. Sin embargo, la inaplicabilidad de este régimen puede ser más perjudicial para el joven si, por ejemplo, se determina su discernimiento y se somete a las reglas que rigen para adultos, vigentes al ejecutar la conducta juzgada. En este sentido se pronuncia la Corte Suprema, el 6 de noviembre de 2008 (ROL 2617-2008), ${ }^{46}$ al preferir el sistema penal juvenil respecto

${ }^{44}$ Así lo dispone expresamente el artículo 26 de la Ley 20.084, cuando señala que "La privación de libertad se utilizará sólo como medida de último recurso" y que "En ningún caso se podrá imponer una pena privativa de libertad si un adulto condenado por el mismo hecho no debiere cumplir una sanción de dicha naturaleza".

${ }^{45}$ C. de Ap. de San Miguel, 23 de septiembre de 2008, Legal Publishing: 40373.

46 Ver http://www.poderjudicial.cl/index2.php?pagina1=estados_causas.php [consulta, 2 de diciembre de 2008]. Al respecto, se subrayan resoluciones que alteran la naturaleza de la sanción, como la sentencia 
de un sujeto de 23 años, que tenía 17 al cometer el delito, a pesar de no regir en dicho momento. Destaca la alteración del juzgamiento basada en la existencia posterior de penas menos rigorosas. Llama la atención, eso sí, el argumento esgrimido para su admisión, que ellas proceden como garantía para el adolescente "no sólo en atención a su menor culpabilidad, sino a la necesidad de proteger su desarrollo”, y se extienda esta idea cuando el sujeto ya es adulto. ${ }^{47}$

No siempre la aplicación de normas con base en una interpretación más beneficiosa es real. En este sentido, los tribunales han establecido la sanción del joven por robo con fuerza en lugar habitado o destinado a la habitación como consumado desde que está en grado de tentativa. Por ejemplo, la Corte de Apelaciones de Santiago, en agosto de $2008,{ }^{48}$ señala que aunque el art. 21 de la LRPA remite al art. 51 del Código Penal, es una regla general que cede ante la especial del art. 450 de dicho código, por lo que procede esta última que equipara las penas. El fallo reconoce, adecuadamente, que la ley no innovó en esta materia, la dejó intacta. En realidad, sostiene que la aplicación del Código Penal es independiente de las reglas del régimen penal juvenil. Ocurre que existe un problema de regulación de la parte general. No hay disposiciones especiales relativas a la conducta delictiva, a la clase de circunstancias agravantes y atenuantes, a las reglas de participación, de desarrollo del delito, etc., sino únicamente un sistema distinto de penas. ${ }^{49}$

La misma sentencia reconoce que el actual régimen de responsabilidad no establece un sistema más beneficioso "per se", ${ }^{50}$ pero la naturaleza de las sanciones sí es más benigna. Ellas tienen un carácter socioeducativo y están dirigidas a la integración social del adolescente. Se destaca esta idea en función de la calidad especial del agente, su condición de joven en desarrollo. Su considerando décimo indica que "no es lógico ni razonable sostener que, a sus 26 años de edad, el sentenciado pueda ser sujeto susceptible de los mecanismos de intervención socioeducativa previstos para un adolescente o que éstos sean verdaderamente idóneos para fortalecer las necesidades de desarrollo e integración

de la CS., 5 de mayo de 2008, Legal Publishing: 39077, que sustituye la pena privativa por servicios a la comunidad como sanción asignada al delito, aunque no haya estado vigente al momento de su comisión.

${ }^{47}$ Ello choca aún más respecto del principio de separación entre jóvenes y adultos. De todas formas, puede cumplirse en un recinto carcelario, según el art. 56 de la Ley 20.084, aunque el procedimiento no parece reservarse para casos con tanta diferencia de edad ("Si al momento de alcanzar los dieciocho años le restan por cumplir más de seis meses...").

${ }^{48}$ C. de Ap. de Santiago, 19 de agosto de 2008, Legal Publishing: 39770.

${ }^{49}$ Esta omisión choca con la idea de que los delitos no se consideran ni comenten de igual manera que los adultos. Bustos Ramírez, Derecho penal..., pp. 24-28, la considera una falla conceptual, que no sólo hace aplicable las normas sobre delitos, sino también las reglas de determinación de penas (art. 22 de la ley), cuya regulación es el objetivo principal de la ley. Sólo se contemplan un par de reglas, como la no aplicación de las faltas para el tramo inferior de edad (art. 1.3) y límites para los delitos sexuales (art. 4). De hecho, los tribunales admiten que sólo se establece un régimen especial de sanción. Por ejemplo, la sentencia de la CS., 6 de mayo de 2008, Legal Publishing: 38809. Ello, aunque se mantiene la vinculación con las sanciones del régimen de adultos, del CP. Ver CS., 21 de agosto de 2007, Legal Publishing: 36933.

${ }^{50}$ Por eso hay sentencias que, razonablemente, han rechazado la aplicación retroactiva de la Ley 20.084, como la de la C. de Ap. de Santiago, 14 de abril de 2008, Legal Publishing: 38825. 
social, de quien, a esas alturas y con mucho, habrá dejado de ser un adolescente. En suma, tampoco se cumplen los fines de la sanción". La misma condición del joven agente lleva al sentenciador a no extender esa sanción si éste ya es adulto -a diferencia del fallo de la Corte Suprema de 6 de noviembre de 2008-. ${ }^{51}$

Si bien esa separación tiene lógica, podría privar del carácter resocializador o socializador a las penas y medidas impuestas a los adultos. Toda respuesta penal debiera orientarse en este sentido si se busca que el agente no vuelva a delinquir, ${ }^{52}$ sin desconocer que ello es más evidente cuando se trata de jóvenes en proceso de desarrollo. Idea fundamental para el sistema que los rige por sus especiales características, pero no implica que el régimen para adultos no contemple la reinserción social del reo. En el caso de los adolescentes la relevancia aumenta también porque el sistema se ocupa principalmente de las medidas o consecuencias que proceden. ${ }^{53}$ De hecho -como se ha subrayado-, desde un comienzo se reconoce que, junto con establecer responsabilidad por las conductas realizadas, las sanciones han de orientarse a la educación del menor de edad. El artículo 20 expresamente señala que "las sanciones y consecuencias que esta ley establece tienen por objeto hacer efectiva la responsabilidad de los adolescentes por los hechos delictivos que cometan, de tal manera que la sanción forme parte de una intervención socioeducativa amplia y orientada a la plena integración social”. Dirección que se observa en cada sanción, incluso en las privativas de libertad que contemplan programas de reinserción social (arts. 6, 15-17), así como en las reglas y criterios que se establecen.

\subsection{Carácter de la sanción penal juvenil}

La orientación eminentemente preventiva especial no suprime el carácter sancionador. De allí que la ley comience por establecer la responsabilidad del joven infractor ${ }^{54}$. Toda pena supone un castigo para un sujeto al que se le puede reprochar la comisión de

${ }^{51}$ La omisión de reglas generales para adolescentes facilita la confusión, pero no impide estas consideraciones. De allí que Hernández Basualto, H., "El nuevo...”, pp. 198-201 y 216, sostenga que la falta de regulación obliga al juez a una interpretación diferenciada que respete el menor grado de desarrollo del joven, es decir, que sea más benigna.

52 Aunque algunos pretendan separar las sanciones para jóvenes de las penas por la particular orientación preventiva especial de las primeras. Roca Agapito, El sistema..., p. 449, las distingue. Señala que esa finalidad las acerca más a las medidas de seguridad, sólo que no se fundamentan en la peligrosidad del adolescente sino en su educación. Entiende que son medidas sui generis o híbridas, entre la pena y la medida de seguridad.

${ }^{53}$ El Mensaje de la Ley 20.084, junto con enfatizar la idea resocializadora del menor de dieciocho años, admite que el núcleo de la ley se dirige hacia las consecuencias de la infracción penal. Desde el comienzo se señala que se somete a consideración un "proyecto de Ley relativo a la determinación de las consecuencias jurídicas de las infracciones a la ley penal cometidas por adolescentes”. Precisa que su propósito es reformar radicalmente la "respuesta del Estado" frente a conductas delictivas realizadas por adolescentes.

${ }^{54}$ Art. 1. "Contenido de la ley. La presente ley regula la responsabilidad penal de los adolescentes por los delitos que cometan, el procedimiento para la averiguación y establecimiento de dicha responsabilidad, la determinación de las sanciones procedentes y la forma de ejecución de éstas". 
un injusto penal. Exige su responsabilidad, pero también tiene o debe tener en cuenta su necesidad. Independientemente de las tesis sobre las finalidades y funciones de la pena, las sanciones tienen cierto carácter de pago, de corresponder por el hecho, sin que suponga una retribución absoluta. Se reconocen otros factores personales y circunstanciales importantes a la hora de elegir una pena, así como sus repercusiones comunicativas. Se consideran también criterios de necesidad de pena, de prevención. Puede ser que una sanción, una pena, sea merecida pero no necesaria, por ejemplo en caso de delitos irrepetibles o de sujetos incorregibles -que requieran otras medidas-. También pueden existir penas necesarias, por la clase de conducta (injusta), pero no merecidas.

Criterios de merecimiento y necesidad son básicos a la hora de aplicar estas sanciones. Esto explica que vigente la regulación anterior (hasta 2007) los menores de 18 años no se castigaban con pena por sus conductas ilícitas penales. No se castigaban por falta de merecimiento y no porque no fueran necesarias -lo eran como conductas graves que infringían igualmente la ley penal-. ${ }^{55}$ Los menores de 16 años nunca la merecían y entre 16 y 18 sólo si se determinaba que eran imputables por el juicio de discernimiento. Si bien cambia el merecimiento, los factores de necesidad de pena, de prevención, se conservan pero no son iguales para jóvenes y adultos, tienen que ver con la conducta del agente en particular.

Una de las fallas del sistema anterior era someter a los adolescentes (imputables) a las mismas reglas que los adultos. La necesidad no se explica de la misma manera en caso de sujetos que no están plenamente formados, cuya comprensión puede más fácilmente instruirse. Ideas de socialización y educación se tornan especialmente relevantes en el caso de los jóvenes en proceso de desarrollo. Ellos son imputables, responsables, merecen una pena, pero ésta debe ser acorde a sus condiciones. Por eso el actual sistema se basa tanto en la responsabilidad de estos agentes, como en la búsqueda de su reinserción social, aunque se destaque esta última dirección.

\subsection{Determinación y aplicación de la sanción penal}

A partir de la base de que el régimen de responsabilidad penal juvenil supone específicamente un tratamiento diferenciado respecto de las consecuencias jurídicas que corresponden aplicar, son clave la imposición, determinación y ejecución de las sanciones. Es justamente en este ámbito donde se concretan las características y fines de este sistema de responsabilidad. Juegan aquí sus dos pilares básicos: responsabilidad y educación. Dos criterios que parecen contrapuestos y que se conjugan fundamentalmente al establecer la medida aplicable. ${ }^{56}$ La responsabilidad significa asumir la consecuencia penal y ésta se orienta hacia la reinserción social del adolescente infractor.

55 También una pena merecida puede no ser necesaria, como en caso de delitos irrepetibles o de sujetos incorregibles -aunque requieran otras medidas-.

${ }^{56}$ También en el Mensaje de la ley se destaca esta combinación precisamente al establecer las sanciones. Expresamente señala que las consecuencias jurídicas que han de imponerse "unen a su carácter explícitamente sancionatorio, las funciones responsabilizadora y preventiva en un marco de respeto y resguardo de su desa- 
Las diversas sanciones que se contemplan consagran ambas ideas (art. 6 de la ley) y se evidencia especialmente si se tiene en cuenta que la privación de libertad es excepcional y se establece una amplia gama de respuestas, donde la imposición de servicios a la comunidad pretende ser la regla general. ${ }^{57}$ Este carácter se ha subrayado de modo particular en la sanción de internación en régimen semicerrado. La Corte de Apelaciones de San Miguel en sentencia de julio de $2008,{ }^{58}$ señala que esta consecuencia es una "adecuada solución para una problemática relevante en la sociedad actual, que guarda estrecha relación con una sanción efectiva, y al mismo tiempo dual, que por una parte castigue al culpable por el ilícito perpetrado y por la otra permita una apropiada resocialización y reinserción social”. Sin embargo, esa sanción se modificó por incumplimiento del joven más el quebrantamiento de condena por la comisión de otros delitos. La pena se sustituyó por internación en régimen cerrado. De todas formas, el fallo de la Corte resalta la declaración expresa del Juez a quo en orden a la posibilidad de modificar nuevamente la sanción. Esta internación no sería definitiva, pues cabe que el condenado se recupere y que existan mejores posibilidades de cumplir en libertad.

Destaca no sólo que las mismas sanciones contemplen criterios de reinserción social, ${ }^{59}$ sino que también la ley ordena al juez considerarlos al seleccionar y determinar la pena y durante su ejecución. La ponderación de circunstancias personales del joven obedece a esa idea resocializadora y, en ocasiones, socializadora que tiene en cuenta los efectos de las sanciones para su vida en sociedad. Esta valoración tiene relevancia al elegir la sanción penal y, sobre todo, al determinar su duración. En primer lugar, se indican ciertos límites por la condición del adolescente, que comienzan con la fijación de un mínimo frente a la sanción que le correspondería si fuera adulto. El juez ha de partir de una pena inferior en un grado al mínimo que dispone el Código Penal para el delito en cuestión (art. 21 de la ley). También señala un límite máximo. Las penas privativas de libertad no pueden durar más de 5 años si el joven es menor de 16 años, si tiene más de esa edad el máximo aumenta a 10 años (art. 18 y 22 de la ley). ${ }^{60}$

rrollo e integración social". Ambas consideraciones se condicen con la consagración en textos internacionales de modelos mixtos que combinan la responsabilidad con sistemas educativos.

57 Ello, además de la consagración expresa de programas de integración social. Así, la C. de Ap. de San Miguel, 24 de marzo de 2008, Legal Publishing: 38573, señala que la determinación del contenido de esos programas es "un complemento que fija las condiciones mínimas que deben garantizarse al menor condenado, con el objeto de lograr los objetivos que el artículo 20 del mismo cuerpo legal asigna a las especiales sanciones que el sistema de responsabilidad penal adolescente contempla, esto es, una intervención socioeducativa amplia y orientada a la plena integración social del menor que ha delinquido".

${ }^{58}$ C. de Ap. de San Miguel, 8 de julio de 2008, Legal Publishing: 39653. En general, se ha admitido el juego de ambos fines al establecer sanciones y precisar su cuantía, por ejemplo: CS., 14 de julio de 2008, Legal Publishing: 39394.

${ }^{59}$ Se observa en la descripción de sanciones privativas de libertad, que incorporan los programas especiales mencionados (arts. 6, 15-17), y también en las no privativas, como la libertad asistida-que dispone el control de un delegado según la sujeción a "un plan de desarrollo personal basado en programas y servicios que favorezcan su integración social” (art. 13)-.

${ }^{60}$ Aquí sobresale la diferencia de criterios según tramos de edad (14 y 15 / 16 y 17), que supone otra distinción particular según el estado del sujeto. A ello se suma el límite relativo a la privación de libertad como último recurso (arts. 26, 47). 
Dentro de tales límites, el art. 23 señala reglas para la selección de la naturaleza de la pena. Por ejemplo, si la pena excede de 5 años, el juez debe aplicar la pena de internación en régimen cerrado con programa de reinserción social. ${ }^{61}$ Las penas van cambiando y, en general, el juez podrá optar entre internación en régimen semicerrado con programa de reinserción social, libertad asistida en cualquiera de sus formas y prestación de servicios a la comunidad, si ella es menor de 3 años. La condición del joven se considera en cada clase de sanción, que contempla, a su vez, ciertos límites. Así, la libertad asistida especial tiene una duración máxima de 3 años (art. 14 de la ley). Luego, las características individuales juegan un rol central como criterio de determinación de pena conforme a esos márgenes (específicamente letras d) y f) del art. 24 de la ley). Finalmente, ellas importan durante el cumplimiento de la sanción, por ejemplo, con relación a las condiciones de los centros y sus derechos (arts. 44, 49 letra a)) y las facultades del juez para modificar o dejar sin efecto la sanción (arts. 53-55). Novedades todas que implican la instauración de un nuevo modelo de justicia que ha de examinarse.

\section{Binomio "control / educación" en el ejercicio de la potestad sancionadora}

Las sanciones que se contemplan, la modalidad de determinación y los criterios que se establecen para tal fin conceden al juez la flexibilidad necesaria para adoptar las medidas más adecuadas en cada caso e implican una manifestación clara de principios preventivos especiales. La reforma radical de la respuesta del Estado para la delincuencia juvenil no va tanto por el procedimiento como por las facultades que se conceden al juez a la hora de imponer y hacer cumplir las sanciones. Desde el establecimiento de las sanciones por el legislador se evidencia una diferencia determinante con el régimen de adultos: no se establece una pena para cada delito, sino que se dispone un catálogo de sanciones para que el juez elija y aplique según el caso. El art. 6 de la Ley 20.084 habla de una "Escala General de Sanciones Penales para Adolescentes". ${ }^{2}$ Se fijan como sanciones: internación en régimen cerrado con programa de reinserción social; internación en régimen semicerrado con programa de reinserción social; libertad asistida especial; libertad asistida; prestación de servicios en beneficio de la comunidad; reparación del daño causado; multa, y amonestación. Como penas accesorias están la prohibición de conducción de vehículos motorizados y el comiso de los objetos, documentos e instrumentos de los delitos. También se señala como sanción accesoria la obligación de

${ }^{61}$ Esta regla obligatoria se impuso en la Ley 20.191 de 2007 y se critica frente al carácter excepcional de la privación de libertad, según los principios y convenciones internacionales que rigen este sistema. La crítica va, más bien, por el hecho de poder imponer esta pena privativa respecto de conductas que no son tan peligrosas y debió contemplarse justamente para delitos peligrosos, es decir, para conductas graves que afecten la vida o integridad corporal de las personas, su seguridad e indemnidad sexual. Además, la tabla demostrativa no se modifica y mantiene la opción entre régimen cerrado y régimen semicerrado, ambos con programa de reinserción social si la pena excede de 5 años.

${ }^{62}$ De hecho, la libertad del juez aumenta con la Ley 20.191 al eliminar la diferencia de penas entre delitos y faltas y contemplar un único catálogo. 
someterse a tratamientos de rehabilitación por adicción a las drogas o al alcohol, siempre con atención a las circunstancias del joven (art. 7).

Como se observa, existe un amplio elenco de sanciones penales dentro del cual el juez puede elegir la que le parezca más adecuada. El rasgo principal del sistema penal juvenil se puede resumir en el ejercicio flexible de la potestad sancionadora, ${ }^{63}$ que no es sinónimo de arbitrariedad ni libertad absoluta, pues han de considerarse una serie de factores y límites. El juzgador debe respetar -además de las restricciones y reglas señaladas-, la conducta realizada y, especialmente, las condiciones particulares del adolescente infractor. ${ }^{64}$ En este sentido es claro el art. 24 de la ley. Establece como criterios de determinación de penas para fijar su naturaleza dentro de los límites impuestos, junto con la gravedad del ilícito; la participación del joven; el grado de desarrollo de la infracción; las circunstancias atenuantes o agravantes y extensión del mal causado por el delito, la edad del joven y "la idoneidad de la sanción para fortalecer el respeto del adolescente por los derechos y libertades de las personas y sus necesidades de desarrollo e integración social".

Especialmente a partir de este último criterio destacan las consideraciones personales del agente como guía fundamental para determinar la naturaleza y duración de la sanción penal. ${ }^{65} \mathrm{El}$ juez ha de tener especialmente en cuenta las necesidades del joven infractor, que miran a su reintegración social. Idea fundamental si se busca impedir que vuelva a cometer delitos, controlar la violencia en general. Este proceder refleja el mencionado binomio que marca el carácter de la respuesta penal en este ámbito: una sanción -responsabilidad, merecimiento- que destaca la relevancia de criterios de

63 Esta idea se destaca en el Mensaje de la Ley, aunque podría pasar desapercibida. Indica que el proyecto de ley, en particular, "establece un criterio flexible, a favor del adolescente, en la adjudicación de las sanciones; la posibilidad de dejar sin efecto o sustituir anticipadamente las sanciones por otras menos severas...". Rasgo que no se elimina por determinadas exigencias del legislador, como el deber de imponer una pena privativa de libertad cuando la pena supere los cinco años, pues -como se ha dicho- no sólo incluye programas de reinserción social sino que su conservación se deja en manos del juzgador, que controla su ejecución. También en este sentido se pronuncian otras legislaciones que han influido en la nuestra. Así, la Exposición de Motivos de la ley española en el punto 11 dispone que "la ley establece un amplio catálogo de medidas aplicables, desde la referida perspectiva sancionadora-educativa, debiendo primar nuevamente el interés del menor en la flexible adopción judicial de la medida más idónea, dadas las características del caso concreto y de la evolución personal del sancionado durante la ejecución de la medida”.

${ }^{64} \mathrm{La}$ ley sólo da criterios al juez y no indica reglas especiales de participación, iter criminis o circunstancias modificatorias de responsabilidad penal. Roca Agapito, El sistema..., pp. 458-460, explica justamente esta omisión en el régimen español por la flexibilidad en la adopción y ejecución de medidas, que sería el criterio rector del sistema. Se preocupa de precisar que el juez debe motivar su decisión, conforme esos criterios, sin que la flexibilidad suponga arbitrariedad. También nuestra ley apunta a tal fundamento cuando describe los criterios de determinación de pena. El art. 24 expresa que el juez debe dejar constancia de los que considera en su fallo.

${ }^{65} \mathrm{La}$ edad del joven es relevante en cuanto los distintos grados de desarrollo suponen diverso grado de responsabilidad y de readaptarse o adaptarse socialmente. De allí que se destaque como principio el tramo de edad y nuestra ley haga diferencias según el joven tenga 14-15 o 16-17 años. Otros factores importan para tal integración social, como el entorno familiar, económico, social, que se han de tener en cuenta frente a la idoneidad de la sanción. 
readaptación o adaptación social. Ellos apuntan básicamente a la educación del infractor -necesidad de pena-, en términos de acción constructiva o reconstructiva de aspectos positivos de la personalidad del joven agente responsable y su posterior vida en sociedad. ${ }^{66}$ Esta combinación entre control y educación es la lucha que enfrenta este régimen de responsabilidad. Martínez Serrano ${ }^{67}$ manifiesta que este binomio hace que la justicia de menores se mueva permanentemente en una cuerda floja frente a un difícil equilibrio entre ambos objetivos. Nuestros tribunales han admitido semejante lucha, como el fallo de la Corte Suprema de 14 de julio de $2008^{68}$ que manifiesta este equilibrio al determinar la cuantía exacta de la sanción penal según el art. 24, de acuerdo con los pasos que establece el legislador.

La Corte, luego de citar los pasos para la precisión de la naturaleza y duración de la sanción, comienza por señalar que los criterios del art. 24 consagran un necesario grado de flexibilidad para que el juez seleccione la pena más adecuada y vincula esta flexibilidad con el equilibrio entre los objetivos de la sanción, de la ley en general. ${ }^{69}$ Funda su argumentación en la sentencia del Tribunal Constitucional de 13 de junio de 2007 (Rol N 786 2007). Expresa que semejantes objetivos "no se agotan con la determinación de la pena asignada al delito sino que el juez que la impone tiene un rol activo e integral en asegurar el necesario equilibrio que debe existir entre el intento de rehabilitar al condenado y la necesidad de proteger a la sociedad frente a las conductas delictivas de los adolescentes". ${ }^{70}$ De suerte que también puede estimarse que según las condiciones del joven y la clase de conducta realizada la sanción debe reflejar un mayor control y no ser tan benigna. En este sentido, la Corte de Apelaciones de Santiago ${ }^{71}$ ha preferido imponer una pena que resguarde la seguridad social ante un delito de

${ }^{66}$ En este sentido se asimila a educación y se proyecta hacia su vida en libertad. Ver Neuman, E., Evolución de la pena privativa de libertad y regímenes carcelarios, Ediciones Pannedille, Buenos Aires, 1971, pp. 100, 101. Esta proyección debiera guiar también al juez respecto de sanciones no privativas ni restrictivas de libertad, particularmente al imponer un servicio a la comunidad. No siempre resulta claro cuál se ha de establecer ni conforme a qué criterio. La Exposición de Motivos de la LO 5/2000 española dispone que la actividad que se determine se ha de relacionar con la naturaleza del bien afectado, y se funda en que la característica de esta consecuencia es que el joven comprenda el mal que causó.

${ }^{67}$ Martínez Serrano, Alicia. "Principios sustantivos y procesales básicos de la respuesta penal de los menores establecidos en la LO 5/2000", en Cuadernos de Derecho Judicial, No 3, 2001, p. 22.

${ }^{68}$ CS., 14 de julio de 2008, No Legal Publishing: 39394.

${ }^{69}$ De todas formas, hay que tener presente que esta flexibilidad no excluye la necesaria proporcionalidad entre la sanción y la conducta. La ley considera básico también la gravedad del ilícito y la participación del adolescente. Simplemente, no se trata de una proporcionalidad rígida o estricta, sino atenuada precisamente por tal flexibilidad, que demanda la consideración de la situación concreta del joven y nunca puede servir para aumentar la pena, sino para disminuirla.

${ }^{70}$ Asimismo, en su considerando séptimo, cita el Segundo Informe de la Comisión de Constitución, Legislación Justicia y Reglamento del Senado, de 22 de agosto de 2005, Historia de la Ley $\mathrm{N}^{\circ} 20.084$, p. 639. El sistema de determinación de penas refleja "adecuadamente las finalidades tanto de punición como de rehabilitación y que conjuga equilibradamente las aspiraciones sociales de seguridad y justicia, las necesidades del joven de completar sus procesos de maduración y educación y el necesario grado de compromiso de la familia”.

${ }^{71}$ C. de Ap. de Santiago, 28 de noviembre de 2008, Legal Publishing: 41328. 
homicidio, justamente por el art. 24 de la ley. Toma en cuenta la gravedad de la conducta, la edad del adolescente, muy cercana a la mayoría de edad (17 años) y conecta los efectos de la sanción privativa más grave en su propia conducta: "la sanción que ha decidido imponer es la idónea para fortalecer el respeto del adolescente imputado por los derechos y libertades de las personas, así como sus propias necesidades de desarrollo e integración social, todo lo cual no parece posible que se consiguiera con una pena de tan baja entidad como la que se impuso en primera instancia".

Las facultades que se conceden al juez a la hora de precisar la concreta sanción penal se conservan, de algún modo, durante su ejecución o cumplimiento. En realidad, puede decirse que las consideraciones personales del condenado tienen más relevancia al momento de cumplir la pena. Ello porque ya no importa la conducta ilícita realizada sino la situación del joven que cumple la pena. En ese momento, adquiere especial interés el fin de la sanción vinculado con la educación del infractor, con la posibilidad de que comprenda el mal que causó y se reintegre a la sociedad. Así se observa en los mismos derechos que se reconocen durante la ejecución de la sanción. El primero es el de "ser tratado de una manera que fortalezca su respeto por los derechos y libertades de las demás personas, resguardando su desarrollo, dignidad e integración social” (art. 49 a)). Aprender a respetar los derechos de los demás importa a la hora de reinsertarse a la sociedad. Evaluación que repercute incluso en la conservación misma de la pena.

Durante el control de la ejecución de la sanción penal el juez puede dejar sin efecto la sanción penal con atención a la evolución del joven sujeto a ella. Los arts. 53 y 54 permiten al tribunal modificar la pena por una menos gravosa, de oficio o a petición de parte. Aquí se destaca nuevamente la integración social del infractor como criterio para tal sustitución. Si el juez considera que se han cumplido los objetivos de la sanción, la ley lo faculta también para remitir el cumplimiento de la condena (art. 55). Estas consideraciones especiales del sujeto evidencian un cambio fundamental frente al sistema de adulto y, con ello, al régimen de inimputabilidad relativa que existía. ${ }^{72}$ Se camina hacia un modelo de justicia individualizado, ${ }^{73}$ que considera factores personales no sólo al imponer penas, sino también durante su ejecución. De allí que sea pertinente hablar de "individualización judicial” más que de determinación de penas, donde se refleja el binomio control-educación, sanción e integración social. ${ }^{74}$

Esta combinación se explica en este sistema por la condición del agente, aunque también es deseable en el régimen penal de adultos. De todas formas, se ha de tener

${ }^{72}$ Los mayores de 16 años también se sometían al régimen de adultos si se determinaba su discernimiento.

73 Cerda San Martín, M.; Cerda San Martín, R., Sistema..., pp. 47, 103, 115, 130, 145 y 147, destacan la idea de individualizar pena en un sistema donde se determinan planes individuales y en el que se le ofrecen al juez varias penas equivalentes para que seleccione justamente según "criterios de individualización y razonabilidad".

${ }^{74}$ Justamente, esos autores entienden que la respuesta judicial ha de tener especialmente en cuenta las consideraciones del joven infractor, sus derechos junto con los de la víctima y la sociedad, que se refleja o "manifiesta a través de la dual exigencia de responsabilizarle por el delito cometido a través de la medida impuesta, supuestamente educativa”. Cerda San Martín, M.; Cerda San Martín, R., Sistema..., p. 43. 
claro qué es lo que se le puede pedir al Derecho penal con los sujetos con los que cuenta y a los que se dirige, sin vivir en utopías -que sólo tienen un efecto más negativo, por la frustración de las expectativas no logradas (como los efectos simbólicos de las leyes)-. Luego, un importante rol juega la individualización que realiza el juzgador. De todos modos, se echan en falta -entre otros- mecanismos de control posteriores al cumplimiento de la pena, que quizás no deban ser penales. Pero sí deben existir políticas de seguimiento concretas que se ocupen de recibir al adolescente una vez que haya cumplido su sanción.

\section{BIBLIOGRAFÍA}

Berríos Díaz, G., "El nuevo sistema de justicia penal para adolescentes", en Revista de Estudios de la Justicia, Facultad de Derecho, Universidad de Chile, No 6, 2005, pp. 161-174.

Bustos Ramírez, JuAn, Derecho penal del niño-adolescente (estudio de la Ley de responsabilidad penal adolescente). EJS, Santiago, 2007.

Cerda San Martín, Mónica; Cerda San Martín, Rodrigo, Sistema de responsabilidad penal para adolescentes, $2^{\mathrm{a}}$ ed., Librotecnia, Santiago, 2007.

Cillero Bruñol, Miguel et al., Niños y Adolescentes: Sus derechos en nuestro Derecho, SENAME, Santiago, 1995.

Donovan, Patrick; Oñate, Ximena; Bravo, Gonzalo; Rivera, M. Teresa, "Niñez y Juventud en Situación de Riesgo: La Gestión Social del Riesgo. Una revisión bibliográfica", Última Década, No 28, vol. 16, Santiago, 2008, http://www.scielo.cl/scielo. php?script $=$ sci_arttext\&pid $=$ S0718-22362008000100004\&lng $=$ en\&nrm $=$ iso.

Giménez-Salinas Colomer, E., "La justicia de menores en el siglo XX. Una incógnita”, en $U n$ Derecho penal del menor, Bustos Ramírez, J. (Dir.), ConoSur, Santiago, 1992, pp. 11-53.

Hernández Basualto, H., "El nuevo Derecho penal de adolescentes y la necesaria revisión de su teoría del delito", en Revista de Derecho (2007), vol. XX, No 2, pp. 195-217.

Llobet Rodríguez, J., "La justicia penal juvenil en el Derecho internacional de los derechos humanos", en Anuario de Derecho Constitucional Latinoamericano, México, 2002.

Martínez Serrano, Alicia, "Principios sustantivos y procesales básicos de la respuesta penal de los menores establecidos en la LO 5/2000", en Cuadernos de Derecho Judicial, No 3, 2001, pp. 17-40.

Neuman, E., Evolución de la pena privativa de libertad y regímenes carcelarios, Ediciones Pannedille, Buenos Aires, 1971.

Pérez Sanzberro, G., Reparación y conciliación en el sistema penal, Comares, Granada, 1999.

Roca Agapito, L., El sistema de sanciones en el Derecho penal español, J.M. Bosch, Barcelona, 2007.

Roig Torres, M., La reparación del daño causado por el delito, Tirant Lo Blanch, Valencia, 2000. 
